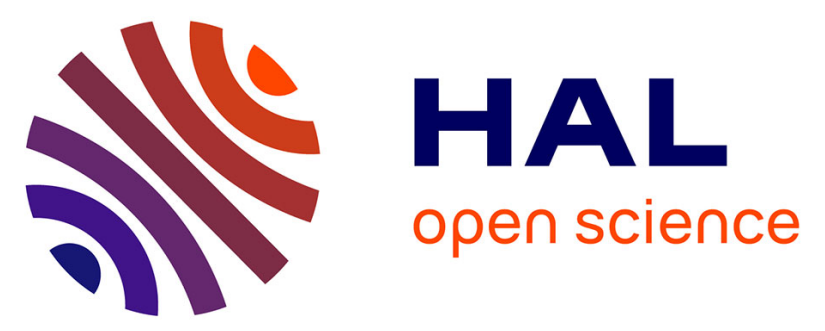

\title{
High resolution kilometric range optical telemetry in air by radio frequency phase measurement
}

\author{
Joffray Guillory, Radek Šmíd, Jorge Garcia-Marquez, Daniel E Truong, \\ Christophe Alexandre, Jean-Pierre Wallerand
}

\section{- To cite this version:}

Joffray Guillory, Radek Šmíd, Jorge Garcia-Marquez, Daniel E Truong, Christophe Alexandre, et al. High resolution kilometric range optical telemetry in air by radio frequency phase measurement. Review of Scientific Instruments, 2016, 87 (7), pp.075105. 10.1063/1.4954180 . hal-02448931

\section{HAL Id: hal-02448931 https://hal-cnam.archives-ouvertes.fr/hal-02448931}

Submitted on 11 Feb 2020

HAL is a multi-disciplinary open access archive for the deposit and dissemination of scientific research documents, whether they are published or not. The documents may come from teaching and research institutions in France or abroad, or from public or private research centers.
L'archive ouverte pluridisciplinaire $\mathbf{H A L}$, est destinée au dépôt et à la diffusion de documents scientifiques de niveau recherche, publiés ou non, émanant des établissements d'enseignement et de recherche français ou étrangers, des laboratoires publics ou privés. 
Joffray Guillory ${ }^{1}$, Radek Šmíd ${ }^{1,3}$, Jorge García-Márquez ${ }^{1}$, Daniel Truong ${ }^{1}$, Christophe Alexandre ${ }^{2}$, Jean-Pierre Wallerand ${ }^{1}$

\author{
${ }^{1}$ Laboratoire Commun de Métrologie LNE-Cnam (LCM), LNE, 1 rue Gaston Boissier, 75015 Paris, France \\ ${ }^{2}$ Centre d'Études et de Recherche en Informatique et Communications (CEDRIC), Cnam, 292 rue St-Martin, 75003 \\ Paris, France \\ ${ }^{3}$ Institute of Scientific Instruments of the CA, Kralovopolska 147, 61264 Brno, Czech Republic
}

We have developed an optical Absolute Distance Meter (ADM) based on the measurement of the phase accumulated by a Radio Frequency (RF) wave during its propagation in the air by a laser beam. In this article, the ADM principle will be described and the main results presented. In particular, we will emphasize how the choice of an appropriate photodetector can significantly improve the telemeter performances by minimizing the amplitude to phase conversion. Our prototype, tested in the field, has proven its efficiency with a resolution better than $15 \mu \mathrm{m}$ for a measurement time of $10 \mathrm{~ms}$ and distances up to $1.2 \mathrm{~km}$.

\title{
I. INTRODUCTION
}

The optical interferometry is commonly used for sub-nanometer distance measurements ${ }^{1,2}$. This technique is however limited to displacement measurements from an initial position, with steps lower than a quarter of the optical wavelength to determine the order of interference fringes without any ambiguity. Additionally, the optical beam must follow continuously the reflective target, with no beam interruption. To overcome these drawbacks, the interferometer can be coupled to an Absolute Distance Meter (ADM) that determines the absolute distance. ADMs are also used outdoor or in harsh industrial environments for distances exceeding a few tens of meters when classical optical interferometry becomes ineffective due to the atmospheric disturbances.

Today, laser trackers are widely used in large scale manufacturing industry. They are very advanced systems achieving indoor, a measurement uncertainty of $\pm 10 \mu \mathrm{m}$ over a range of $100 \mathrm{~m}$. This might be considered to be sufficient, but this value does not take into account the correction from the atmospheric parameters, necessary to know the air refractive index ${ }^{3}$, and so the speed of light along the measurement path. For long range outdoor application, the best state-of-the-art commercial measurement devices claim an uncertainty of $1.6 \mathrm{~mm}$ up to $1 \mathrm{~km}$. Nevertheless, based on early work ${ }^{4,5}$ the Mekometer ME5000 from the former Kern company is the most renowned instrument for geodetic application ${ }^{6,7}$. Its resolution is $100 \mu \mathrm{m}$ but is no more manufactured although still used in several geodetic institutes. In all cases the user has to correct the measurements realized by these instruments from the air refractive index effect. 


\section{This manuscript was accepted by Rev. Sci.Instrum. Click here to see the version of record.}

AlP $P_{\text {ine }}$

Publishing local sensors, even if the relevant parameters should be integrated all along the measurement beam path. Temperature and air pressure are the most critical measurands in the determination of the air refractive index. Indeed, a temperature error of $1{ }^{\circ} \mathrm{C}$ accounts for $10^{-6}$ in the relative error on the distance measurement (i.e. $1 \mathrm{~mm}$ over $1 \mathrm{~km}$ ) while a pressure error of 1 $\mathrm{hPa}$ accounts for $310^{-7}$ (i.e. $300 \mu \mathrm{m}$ over $1 \mathrm{~km}$ ). To achieve a sub-millimetric accuracy over $1 \mathrm{~km}$, a solution - described in ${ }^{9}$ - consists in using two optical wavelengths and taking advantage of the knowledge of air index dispersion between these wavelengths in order to compensate the fluctuations of the air refractive index with temperature and pressure. To obtain a sub-millimetric uncertainty, the distance measurements have to be made at both wavelengths simultaneously with a much better uncertainty on each wavelength. The lower the dispersion between both wavelengths, the better is the requirement on the measurement uncertainty at each wavelength. For instance, for the couple $1550 \mathrm{~nm} / 780 \mathrm{~nm}$, the uncertainty required is $20 \mu \mathrm{m}$ for individual wavelength measurement while it is only $50 \mu \mathrm{m}$ for the couple $1064 \mathrm{~nm} / 532 \mathrm{~nm}$ for a global uncertainty of $1 \mathrm{~mm}$.

A two-wavelength telemeter operating at $441.6 \mathrm{~nm}$ and $632.8 \mathrm{~nm}$ has already been developed in the past ${ }^{10,11}$. Some units were even marketed and called "Terrameter". Large geodetic networks were measured with this instrument in the eighties. Today, this instrument is no more in operation because of its quite difficult use, requiring specific skills ${ }^{12}$. Nevertheless, some large scale surveying applications such as distance measurements in high-energy physics facilities would greatly benefit from two-wavelength solutions.

Therefore, we are developing such an ADM that aims to achieve a sub-millimetric accuracy over a kilometric range. Its design is based on widely available off-the-shelf components to remain affordable and adopts digital data processing. The instrument is therefore compact and includes a simple interface in order to facilitate its comparison in the field to other stateof-the-art technologies.

This article presents the first step in the implementation of this instrument: the realization of a one-wavelength telemeter at $1550 \mathrm{~nm}$, a wavelength widely used in the telecommunication industry and where robust and reliable components are available.

\section{EXPERIMENTAL SETUP}

In the here exposed $\mathrm{ADM}$, the distance is determined from the measurement of the phase accumulated by a Radio Frequency (RF) carrier during its propagation in air. The conversion of this phase shift into distance is deduced as follows:

$$
2 \times D=\left(\frac{\phi}{2 \pi}+k\right) \times \Lambda \text { with } \Lambda=\frac{c}{n \cdot f_{R F}}
$$




\section{This manuscript was accepted by Rev. Sci.Instrum. Click here to see the version of record.}

A A P $P_{0}$

$D$ is the distance, $\Phi$ the phase shift measured along the path, $c$ the speed of light in vacuum, $n$ the group refractive Publi.shing

within the distance to be measured.

The resolution on the measured distance depends on the synthetic wavelength. Our preliminary tests ${ }^{13}$ were conducted at a frequency of $1310 \mathrm{MHz}(\Lambda=23 \mathrm{~cm})$ but, with the aim of continuous improvement, we have opted in the current developments for higher modulation frequencies: tests have been performed at $4261.0 \mathrm{MHz}(\Lambda=7 \mathrm{~cm})$ and at $5910.5 \mathrm{MHz}$ $(\Lambda=5 \mathrm{~cm})$. However, a high modulation frequency involves an ambiguity in the value of $\mathrm{k}$. Thus, to determine the number of synthetic wavelengths $\Lambda$ within the distance to be measured, we also need to carry out distance measurements at low RF carriers. For this purpose, a second frequency synthesizer, with a tunable RF carrier ranging from a few $\mathrm{kHz}$ up to several $\mathrm{MHz}$, is used by changing the state of electrical switches (SWE on figure 1).

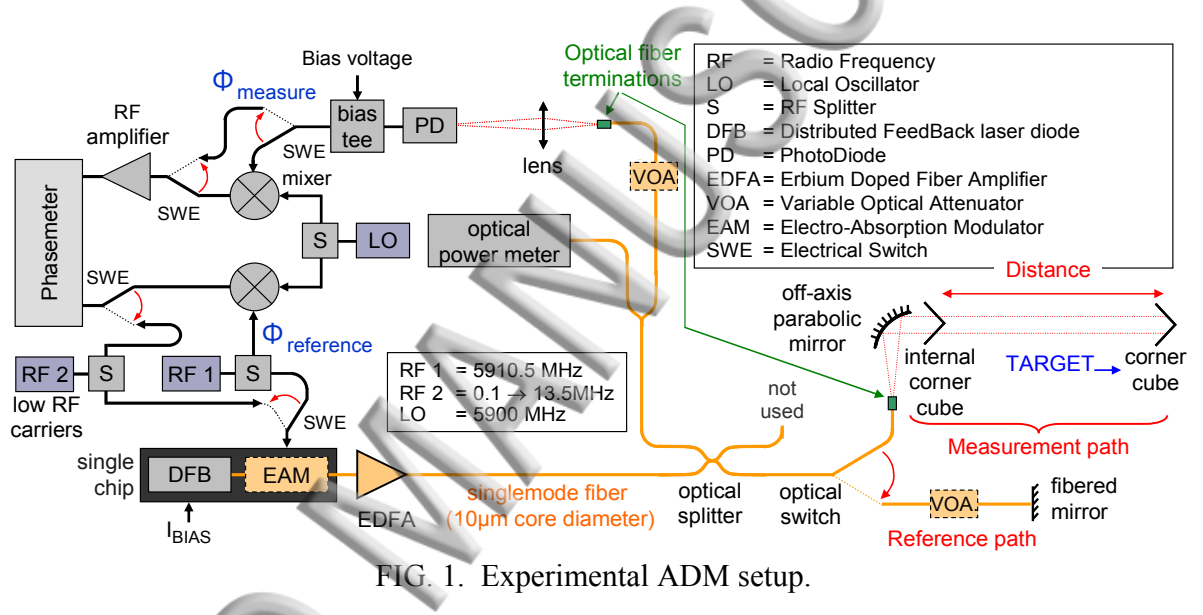

Any distance is measured from the difference between the phase of the RF carrier at the synthesizer output and the same $\mathrm{RF}$ carrier that has been propagated in air by an optical beam. As depicted in Figure 1, this optical carrier, at $1550 \mathrm{~nm}$, is emitted by a temperature-controlled Distributed FeedBack (DFB) laser diode, intensity modulated by a RF signal using builtin Electro-Absorption Modulator (EAM), and amplified by an Erbium-Doped Fiber Amplifier (EDFA) before to pass through a $2 \times 2$ singlemode fiber-optic splitter that plays the role of a circulator. All these optoelectronic components are widely available on the market coming from the telecommunication industry and by this way, the ADM remains affordable.

At the output of the singlemode non polarization-maintaining fiber, the optical beam is emitted in free space to be propagated over a long distance. To this end, we have designed our own optical head. As shown in Figure 2, we have chosen a $90^{\circ}$ off-axis parabolic mirror to collimate the optical beam over a long distance. Thus the setup is achromatic and so ready to be used with another wavelength than $1550 \mathrm{~nm}$, for instance with a visible laser for alignment purpose. This mirror - of 51 $\mathrm{mm}$ of diameter - is placed at $152 \mathrm{~mm}$ from the fiber termination, giving a spot size of $44 \mathrm{~mm}$ at $1550 \mathrm{~nm}$ (at $1 \%$ power level) due to the 0.14 numerical aperture of the single mode fiber we used. 


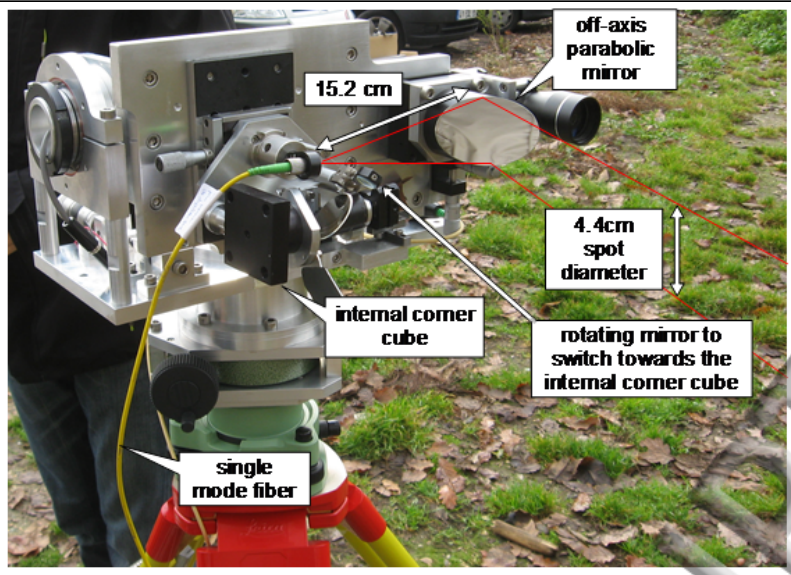

FIG. 2. Photograph of the optical head.

After reflection on a corner cube of $127 \mathrm{~mm}$ diameter (the target) and focalization on the return path by the same $90^{\circ}$ offaxis parabolic mirror, the beam is reinjected into the same singlemode fiber, which induces at least $9 \mathrm{~dB}$ optical losses in optimal alignment conditions. Finally the signal is detected by an Indium Gallium Arsenide (InGaAs) photodiode, then down-converted by a Local Oscillator (LO) into an intermediate frequency of $10.5 \mathrm{MHz}$ before amplification. This approach has two advantages: first, the system is less sensitive to the amplitude to phase (AM/PM) coupling occurring in the electronic stages, and secondly, this enables the use of affordable Analog-to-Digital Converters (ADC) working at $245 \mathrm{MSa} / \mathrm{s}$ with a resolution of 14 bits. The phasemeter itself, based on a homemade designed Field-Programmable Gate Array (FPGA), provides a resolution better than $50 \mu \mathrm{rad}$ for a measurement time of $10 \mathrm{~ms}$. Its operating frequency range covers $100 \mathrm{kHz}$ to $100 \mathrm{MHz}$ with optimal performances between $10 \mathrm{MHz}$ and $20 \mathrm{MHz}$.

However, the optoelectronic and microwave components introduce drifts on the phase measurement caused, for example, by temperature changes or mechanical movement of fibers. To compensate these phase changes, an optical switch was set up as close as possible to the optical fiber termination to periodically - every $250 \mathrm{~ms}$ - measure the phase of the RF signal after propagation on a fiber-optic link (few centimeters) terminated by a fibered mirror (optical switch and reference path are depicted on figure 1). Since this fiber-optic distance is supposed to be fixed, all phase variations observed on this reference path will be interpreted as drifts from the system and so removed from the measured distance:

$$
\phi=\phi_{\text {measure }}-\phi_{\text {reference }}
$$

where $\Phi_{\text {measure }}$ is the phase shift on the measurement path (fiber-optic link and free-space propagation) and where $\Phi_{\text {reference }}$ is the phase shift on the reference path (fiber-optic link only). This fiber optic reference is well adapted for short term reference but evolves for period of minutes or day-to-day. To compensate this medium/long term drift a small corner cube (called internal corner cube), visible on the photograph of figure 2, was mounted on the optical head of the ADM. The free-space beam can then be deviated towards this internal corner cube thanks to a rotating mirror placed at the fiber output (in that case 


\section{This manuscript was accepted by Rev. Sci.Instrum. Click here to see the version of record.} optical head is quite stable this reference measurement is performed only every 5 or 10 minutes.

Thus the final distance is measured as the difference between this internal corner cube and a second one placed far away (called the target). Therefore, the distance $D$ is calculated in the following manner:

$$
D=\left(D_{\text {measure path }}-D_{\text {reference path }}\right)_{\text {internal corner cube }}-\left(D_{\text {measure path }}-D_{\text {reference path }}\right)_{\text {target corner cube }}
$$

Lastly, it has to be noticed that all the fiber components have angle polished connectors in order to minimize back reflections in the optical setup. Indeed, if a small reflected signal (i.e. crosstalk) is added to the measurement signal, nonlinearity in the distance measurement will appear. In order to verify whether this effect can be neglected, the optical crosstalk is estimated by cutting the free-space measurement beam and by checking that the level of the detected RF signal is below 80 $\mathrm{dBm}$. This procedure ensures a non-linearity below 3-5 $\mu \mathrm{m}$ (confirmed by tests on a $3 \mathrm{~m}$ long interferometric bench).

\section{AM/PM CONVERSIONS}

As already explained in Ref 14, the system is limited by the AM/PM conversions occurring in the reception stage of the telemeter, mainly in the photodiode. Indeed, after long distance propagation, the received light is subjected to a high intensity noise due to beam bending and scintillation events in air. For that reason we have quantified in our previous work ${ }^{14}$ the $^{-1}$ AM/PM coupling for three different kinds of InGaAs photodetectors: a Metal-Semiconductor-Metal (MSM), an avalanche and a Schottky photodiode. At that time, the MSM photodiodes, a G7096-03 from Hamamatsu (Table 1), was used in the telemeter and it turned out that it was not the best choice.

Since then, we have completed our tests with a Positive-Intrinsic-Negative (PIN) InGaAs photodiode, the EM169-03 from EM4 (Table 1). The latter presents a very small AM/PM coupling compared to the other technologies. In fact, this photodiode has been characterized using a similar setup than the one presented in ref 14-Fig. 2, but with a RF carrier equal to $4261 \mathrm{MHz}$ instead of $1310 \mathrm{MHz}$. The comparison is presented in Figure 3: it represents the phase shift variations (PM record) induced by the photodetectors and the reception electronic stages when a Variable Optical Attenuator (VOA) based on a MicroElectroMechanical System (MEMS) is square-wave modulated to produce sudden optical power changes equal to $1 \mathrm{~dB}$ (AM generation). For convenience, the phase shift variations have been converted into distances: the y-axis represents the distance variations for optical power variations of $1 \mathrm{~dB}$. 


\begin{tabular}{|c|c|c|c|}
\hline & \multicolumn{3}{|c|}{$\begin{array}{l}\text { This manuscript was accepted by Rev. Sci.Instrum. Click here to see the version of record. } \\
\text { TABLE I. Summary of the characteristics of the two InGaAs photodiodes. }\end{array}$} \\
\hline \multirow[t]{8}{*}{ Publishing. } & & MSM Photodiode & PIN Photodiode \\
\hline & Reference & Hamamatsu G7096-03 & EM4 EM169-03 \\
\hline & Active area dimension & $200 \times 200 \mu \mathrm{m}^{2}$ & $32 \mu \mathrm{m}$ diameter \\
\hline & Bias voltage & fixed to $12 \mathrm{~V}$ (not integrated bias tee) & fixed to $5 \mathrm{~V}$ (built-in bias tee) \\
\hline & Wavelength range & {$[850-1650] \mathrm{nm}$} & {$[1280-1620] \mathrm{nm}$} \\
\hline & RF bandwidth & rise / fall times of $40 / 120 \mathrm{ps}$ & 20GHz@-3 dB \\
\hline & $\begin{array}{l}\text { Typical responsivity } \\
\text { Coupling }\end{array}$ & $\begin{array}{l}0.4 \mathrm{~A} / \mathrm{W} @ 1310 \mathrm{~nm} \\
\text { free-space detector }\end{array}$ & $\begin{array}{c}0.95 \mathrm{~A} / \mathrm{W} @ 1545 \mathrm{~nm} \\
\text { pigtailed detector (SMF-28 FC/APC) }\end{array}$ \\
\hline & Maximum input power & $2 \mathrm{~mW}$ & $6 \mathrm{~mW}$ \\
\hline
\end{tabular}

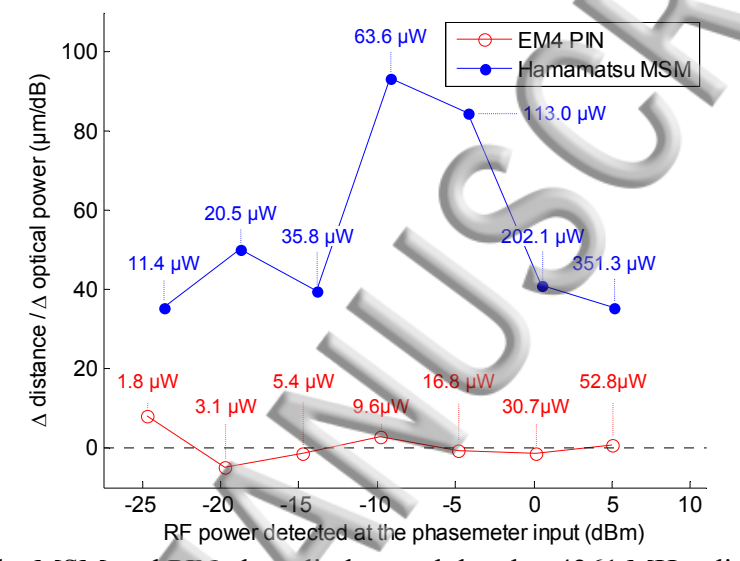

FIG. 3. Comparison between the MSM and PIN photodiodes modulated at $4261 \mathrm{MHz}$ : distance variations as a function of the RF power detected by the phasemeter. The power values indicated in this graph correspond to the maximum values of the square optical power function. The photodiode bias voltages were fixed at 5 and $12 \mathrm{~V}$ for the PIN and MSM photodiodes, respectively.

The results in Figure 3 are plotted as a function of the RF power detected by the phasemeter. Due to significant differences between the photodiode efficiencies and the fiber-to-photodiode couplings, Figure 3 shows a RF power difference at the phasemeter input of $15 \mathrm{~dB}$ for a same optical power illuminating both photodetectors. Thus, in order to obtain the same RF powers (between $-25 \mathrm{dBm}$ and $+5 \mathrm{dBm}$ ), the PIN photodiode should receive an optical power comprised between $1.8 \mu \mathrm{W}$ and $52.8 \mu \mathrm{W}$, while the MSM photodiode should receive an optical power between $11.4 \mu \mathrm{W}$ and $351.3 \mu \mathrm{W}$.

The EM4 PIN photodiode (the same we used in our measurements) was characterized in ref 15 , at higher optical powers (up to $6 \mathrm{~mW}$ ) and higher bias voltages (up to $20 \mathrm{~V}$ ). Their measurements of the phase as a function of the optical power [ref 15, Fig. 2] show that the dependence of these two parameters becomes very low for an optical power below $1 \mathrm{~mW}$ (bias voltage of $12 \mathrm{~V}$ ). This is in agreement with our measurements. However, contrary to ref 15, we did not observe transient response after a sudden change of the optical power, probably because the heating of our photodiode, proportional to the product of the bias voltage $(5 \mathrm{~V})$ and the photocurrent $(50 \mu \mathrm{A})$, was low in our case.

In addition to amplitude to phase conversions, we observed for the MSM photodiode a strong dependence of the phase of the detected RF signal on the position of the focused light onto the active area of the photodiode. A displacement of the spot 

does not affect the accuracy and the resolution of our measurements.

In the next section, the two photodiodes are compared when used for outdoor distance measurements up to $1.2 \mathrm{~km}$.

\section{DISTANCE MEASUREMENTS UP TO $1.2 \mathrm{KM}$}

The developed system was characterized outdoor for distances up to $1.2 \mathrm{~km}$. The MSM photodiode was tested in November 2014 during a calm day with a light wind of $14 \mathrm{~km} / \mathrm{h}$. The sky was partly cloudy, the temperature about $10{ }^{\circ} \mathrm{C}$ and the humidity around $82 \%$. The PIN photodiode was tested in April 2015 during also a calm, but a bit cloudier, day. The temperature was about $12{ }^{\circ} \mathrm{C}$. Both measurements were realized during favorable days when the atmosphere was quite stable. Since then, other tests were conducted with less favorable conditions, more sunny and windy, but no significant difference with results presented here was observed.

Between both measurements the system has evolved, in particular the laboratory synthesizers working at $5910.5 \mathrm{MHz}$ has been changed for more compact solutions based on a Voltage Controlled Oscillator (VCO) and a Phase-Locked Loop (PLL) working at $4261.0 \mathrm{MHz}$.

A procedure to determine $\mathrm{k}$, the integer number of synthetic wavelengths $\Lambda$ within the measured distance (formula 1 ), was also implemented. In this case, as depicted in Figure 1, RF switches were added to the system to, on the one hand, enable the modulation of the laser diode at low frequency by a Direct Digital Synthesizer (DDS) and, on the other hand, enable direct phase measurements without down-conversion. The lowest frequency is $100 \mathrm{kHz}$ and corresponds to a half synthetic wavelength of $1499 \mathrm{~m}$ (or $2998 \mathrm{~m}$ for the round trip up to the corner cube). Thus, a coarse value of the corner cube position was obtained with a resolution slightly higher than $1 \mathrm{~m}$. The distance measurement was then refined by increasing gradually the RF carrier: six different frequencies were used within the range $100 \mathrm{kHz}-13.5 \mathrm{MHz}$. Finally, a resolution of approximately $10 \mathrm{~mm}$ was obtained at $13.5 \mathrm{MHz}$, sufficient to determine without any ambiguity the number of synthetic wavelengths at $4261.0 \mathrm{MHz}$, i.e. to calculate $\mathrm{k}$. In the example of Figure 4, the coarse measurement provides a distance of $449.092 \mathrm{~m} \pm 7.3 \mathrm{~mm}$ (at $1 \sigma$ ), which corresponds to a k value of 12766 at $4261.0 \mathrm{MHz}$. 


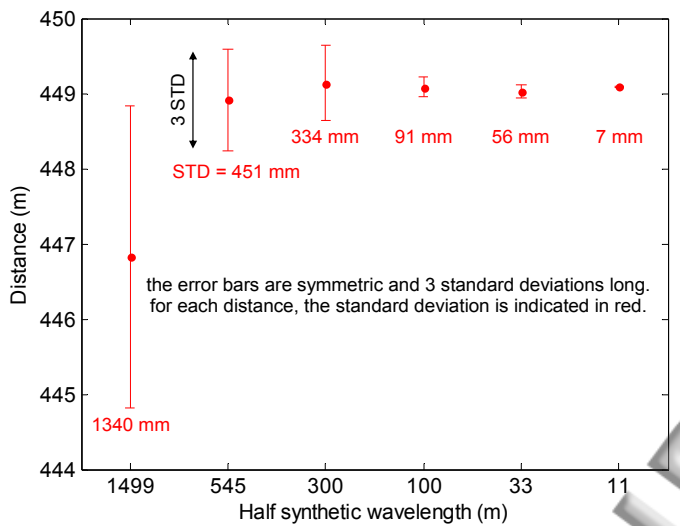

FIG. 4. Results at $449 \mathrm{~m}$ using the PIN photodiode: determination of the number of synthetic wavelengths $\Lambda$ within the distance to be measured.

The comparison between the two photodiodes, MSM and PIN, is focused on the resolution of the ADM. We define this resolution as the standard deviation on valid points within 7300 successive distance values, which requires less than one minute. Each individual point contains amplitude and phase information of RF signals integrated over $10 \mathrm{ms:}$ one measurement is considered as valid if the detected RF power is higher than $-45 \mathrm{dBm}$, i.e. the beam alignment is not completely lost, and lower than $9 \mathrm{dBm}$, i.e. the amplifiers are not saturated.

In a first time, we have quantified the performances of our system when the MSM Photodiode is used. For a short distance of $20 \mathrm{~m}$, the standard deviation was $12 \mu \mathrm{m}$, i.e. a relative resolution of $6 \times 10^{-7}$. When the measured distance increased, the standard deviation increased proportionally. For example, for a distance of $410 \mathrm{~m}$ as represented in Figure 5, the standard deviation has reached $114 \mu \mathrm{m}$, i.e. a relative resolution of $3 \times 10^{-7}$.

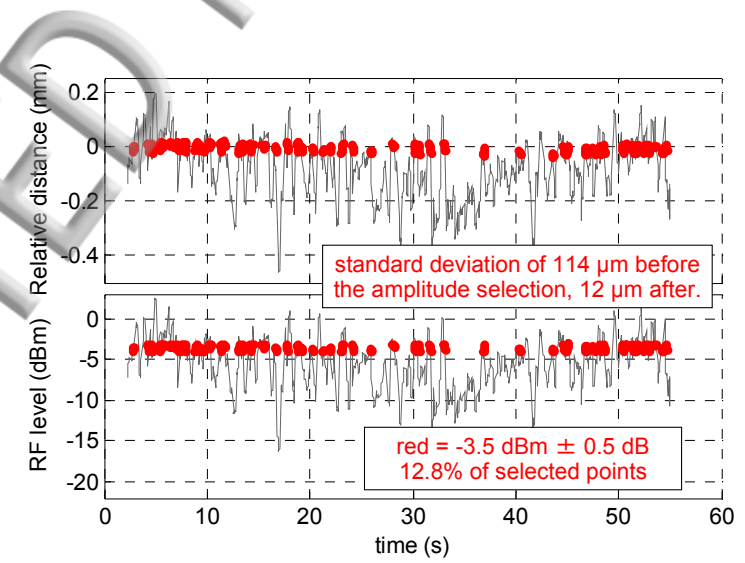

FIG. 5. Results at $410 \mathrm{~m}$ using the MSM photodiode: relative distances and corresponding RF levels as a function of time. Raw data are in grey and selected points in red. The distances are represented in relative (subtraction of the mean) to facilitate the readability of the distance variations. 


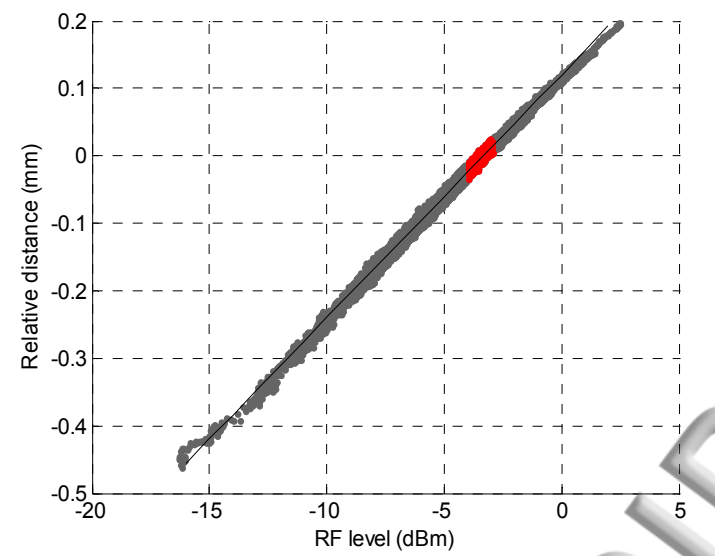

FIG. 6. Results at $410 \mathrm{~m}$ using the MSM photodiode: relative distances as a function of the detected RF levels (raw data in grey and selected points in red).

Figure 5 shows a clear correlation between amplitude variation of the detected RF signal and the measured distance. Figure 6 shows an amplitude to distance conversion factor of $36 \mu \mathrm{m} / \mathrm{dB}$ over a range from $-15 \mathrm{dBm}$ to $3 \mathrm{dBm}$. To improve the resolution of the telemeter, we propose to select the distance values having the same amplitude. To this end, and to avoid the introduction of systematic errors on the measured distance, a proper reference amplitude has to be chosen. In our case, this reference is the amplitude of the reference path since, in our measurement procedure, the measured distance is always compared to it as stated in formula 3. This ensures that the two signals - measure and reference - induce the same amplitude to phase coupling. In practice, we adjust by means of a variable optical attenuator the signal amplitude of the reference path to the average value of the measurement path.

As shown in Figure 5, this solution is very effective. For a distance of $410 \mathrm{~m}$, the standard deviation has been reduced to $12 \mu \mathrm{m}$ by selecting the values with amplitude equal to $-3.5 \mathrm{dBm} \pm 0.5 \mathrm{~dB}$. The relative resolution is thereby equal to $3 \times 10^{-8}$, which represents an improvement by a factor of ten compared to the raw data. The drawback of this procedure is that with a range of $\pm 0.5 \mathrm{~dB}$, the number of relevant points is significantly reduced, especially when the measured distance increases. For instance, for a distance of $410 \mathrm{~m}, 13 \%$ of the captured points were exploitable and only $4 \%$ of them at $970 \mathrm{~m}$.

This phenomenon was not observed when using the PIN photodiode. In that case, the distance values were not correlated to the detected RF levels since this photodiode presents a very small AM/PM coupling. Thus, the data selection described above was not applied. In practice, the minimal acceptable RF level was nevertheless raised from $-45 \mathrm{dBm}$ to $-15 \mathrm{dBm}$ to slightly improve the standard deviation for distances higher than $1 \mathrm{~km}$. Indeed, the ADM resolution significantly deteriorates when the RF signal at the phasemeter input becomes lower than $-20 \mathrm{dBm}$.

An example of the results obtained with the PIN photodiode is presented in Figure 7 for a distance of 449 m, a distance equivalent to the results depicted in Figure 5 where the MSM photodiode was used. 


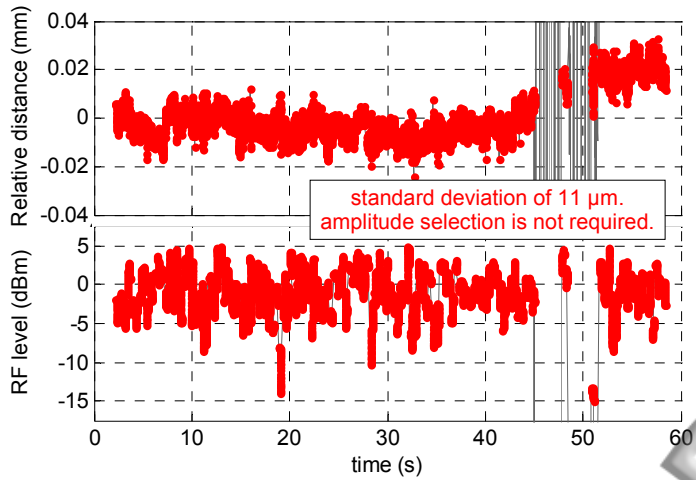

FIG. 7. Results at $449 \mathrm{~m}$ using the PIN photodiode: relative distances and corresponding RF levels as a function of time (raw data in grey and selected points in red). The sudden variations in grey correspond to a laser beam that has been cut.

Nevertheless, the distance resolution of our system is still limited by the knowledge of the refractive index of air. Up to now, we have fixed $\mathrm{n}$ to 1 . As a consequence, change in the atmospheric parameters during the measurement process introduces drifts in the distance measurements. For example, a linear drift of $122 \mu \mathrm{m}$ has been observed in Figure 8 for a distance of $970 \mathrm{~m}$ (MSM photodiode). As we did not observe such a drift for shorter distances (100 $\mathrm{m}$ for instance) we are confident that this drift is a real distance variation or a change in the atmospheric parameters. This drift can be explained for instance by an average temperature change of only $0.13^{\circ} \mathrm{C}$ over $970 \mathrm{~m}$ and it should be removed by the two-wavelength system we are currently developing. Nevertheless, we can already simulate the temperature-compensated distance removing these drifts by a first or second order polynomial curve fitting. Thus, in Figure 8, the corrected standard deviation equals to $12 \mu \mathrm{m}$ instead of $37 \mu \mathrm{m}$ with the only amplitude selection.

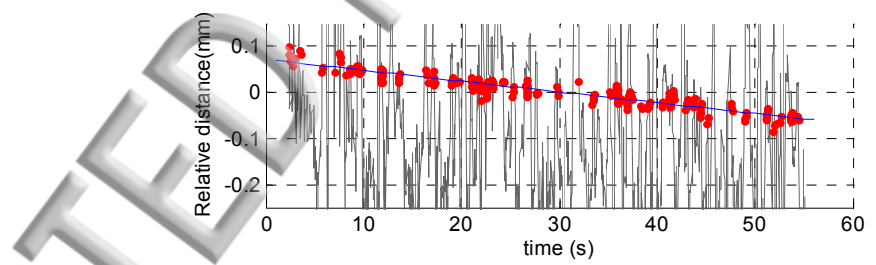

FIG. 8. Linear drift of $122 \mu \mathrm{m}$ (in blue) for a distance of $970 \mathrm{~m}$ when using the MSM photodiode (raw data in grey and selected points in red).

Figure 9 summarizes measurement results: using the MSM photodiode, the standard deviation of raw data increases linearly with the distance up to $200 \mu \mathrm{m}$ at $1 \mathrm{~km}$ (for RF level between $-45 \mathrm{dBm}$ and $+9 \mathrm{dBm}$ ). With a selection of distance values corresponding to an amplitude equal to the reference path $( \pm 0.5 \mathrm{~dB})$, the standard deviation is always less than $36 \mu \mathrm{m}$. Lastly, if the long-term drift is removed to simulate stable atmospheric parameters, we always obtain a standard deviation better than $15 \mu \mathrm{m}$.

Using the PIN photodiode, the data selection is not necessarily required. Thus, in Figure 9, the raw results for the PIN photodiode are overlapped by the selected data (minimum acceptable RF level risen to $-15 \mathrm{dBm}$ ), except for the last point corresponding to a distance of $1162 \mathrm{~m}$. Finally, we always obtained a standard deviation better than $15 \mu \mathrm{m}$ after removing the 


\section{This manuscript was accepted by Rev. Sci.Instrum. Click here to see the version of record.}

drifts, like for the MSM photodiode. Nevertheless, the number of acceptable measurement data is more important: Publishhing gr the PIN photodiode instead of $4 \%$ for the MSM photodiode at around $900 \mathrm{~m}$. For a kilometric range, the same number of valid measurement points can be obtained approximately 20 times faster with the PIN photodiode than with the MSM photodiode. When the weather is more sunny and windy the number of valid measurement points is lower because of stronger amplitude variations, but the distance measurement is still possible and no significant difference of the standard deviation is observed.

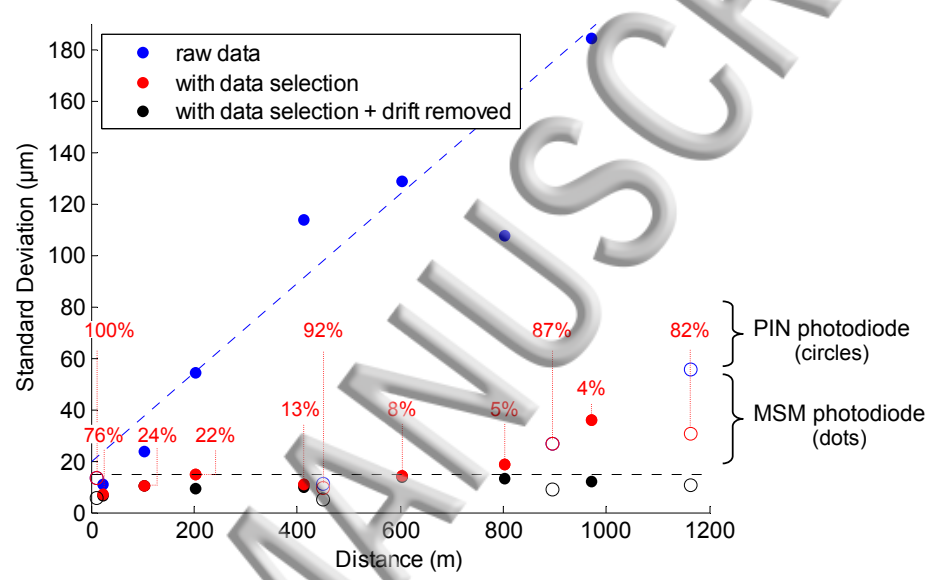

FIG. 9. Standard variation over the measured distances as a function of the absolute distance. In blue: raw data; in red: data selection taking into account RF level; in black: data selection and drift removing. For each colour, dots are for MSM photodiode while circles are for PIN photodiode. The percentages of selected points are indicated in red.

\section{CONCLUSION}

We have presented our first step in the realization of an air index compensated telemeter, consisting in the development of a high resolution telemeter working at $1550 \mathrm{~nm}$. We have demonstrated a resolution of $15 \mu \mathrm{m}$ for a range of operation up to $1.2 \mathrm{~km}$, even when a strong amplitude noise was observed on the optical beam due to air turbulence. We have also shown that the choice of a PIN photodiode, rather insensitive to the amplitude to phase coupling, improved significantly the telemeter performances: the major part of data was relevant and could be kept for distance measurements. The final step of our development will consist in adding a second wavelength (around $780 \mathrm{~nm}$ ) in order to realize simultaneous measurements at both wavelengths to implement real time air index compensation.

\section{ACKNOWLEDGMENTS}

This work was partly funded by the European Metrology Research Programme (EMRP). The EMRP is jointly funded by the EMRP participating countries within EURAMET and the European Union. 


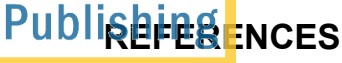

${ }^{1}$ F. C. Demarest, Meas. Sci. Technol. 9, 1024 (1998).

${ }^{2}$ N. Bobroff, Meas. Sci. Technol. 4, 907 (1993).

${ }^{3}$ B. Edlén, Metrologia, Vol. 2, No. 2, 71 (1966).

${ }^{4}$ K. D. Froome and R. H. Bradsell, Journal of scientific instruments, vol. 38, 468 (1961).

${ }^{5}$ K. D. Froome and R. H. Bradsell, Journal of scientific instruments, vol. 43, 129 (1966).

${ }^{6}$ Proceedings of the workshop on the use and calibration of the Kern ME5000 Mekometer, Stanford Linear Accelerator center, Stanford University, Stanford, California (1992). (available on : http://www.slac.stanford.edu/pubs/slacreports/ reports03/slac-r-403.pdf).

${ }^{7}$ J. M. Rüeger, Electronic distance measurement, An introduction, (fourth edition, Springer-Verlag Berlin Heidelberg 1996).

${ }^{8}$ G. Bönsch and E. Potulski, Metrologia, Vol. 35, No. 2, 133 (1998).

${ }^{9}$ K. Meiners-Hagen and and A. Abou-Zeid, Measurement Science and Technology, Vol. 19, No. 8, 084004 (2008).

${ }^{10}$ K.B. Earnshaw and E.N. Hernandez, OSA Applied Optics, Vol.11, No. 4, 749 (1972).

${ }^{11}$ L.E. Slater and G.R. Huggett, Journal of geophysical research, vol. 81, No. 35, 6299 (1976).

12 J. Gervaise, "First results of the geodetic measurements carried out with the Terrameter, two-wavelength electronic distance measurement instrument" Geodätischen Seminar über Electrooptische Präzisionsstreckenmessung, München, pp. 213-229 (1983).

13 J. Guillory, J-P. Wallerand, A-F. Obaton and C. Alexandre, Proceedings of the 2014 Conference on Precision Electromagnetic Measurements (CPEM2014), Rio de Janeiro, Brazil, pp. 490-491 (2014).

${ }^{14}$ J. Guillory, J. García-Márquez, C. Alexandre, D. Truong and J-P. Wallerand, Measurement Science and Technology, Vol. 26, No. 8, 084006 (2015).

${ }^{15}$ D.H. Phung, M. Merzougui, C. Alexandre, and M. lintz, IEEE Journal of Lightwave Technology (JLT), Vol. 32, No. 20, 3759 (2014). 


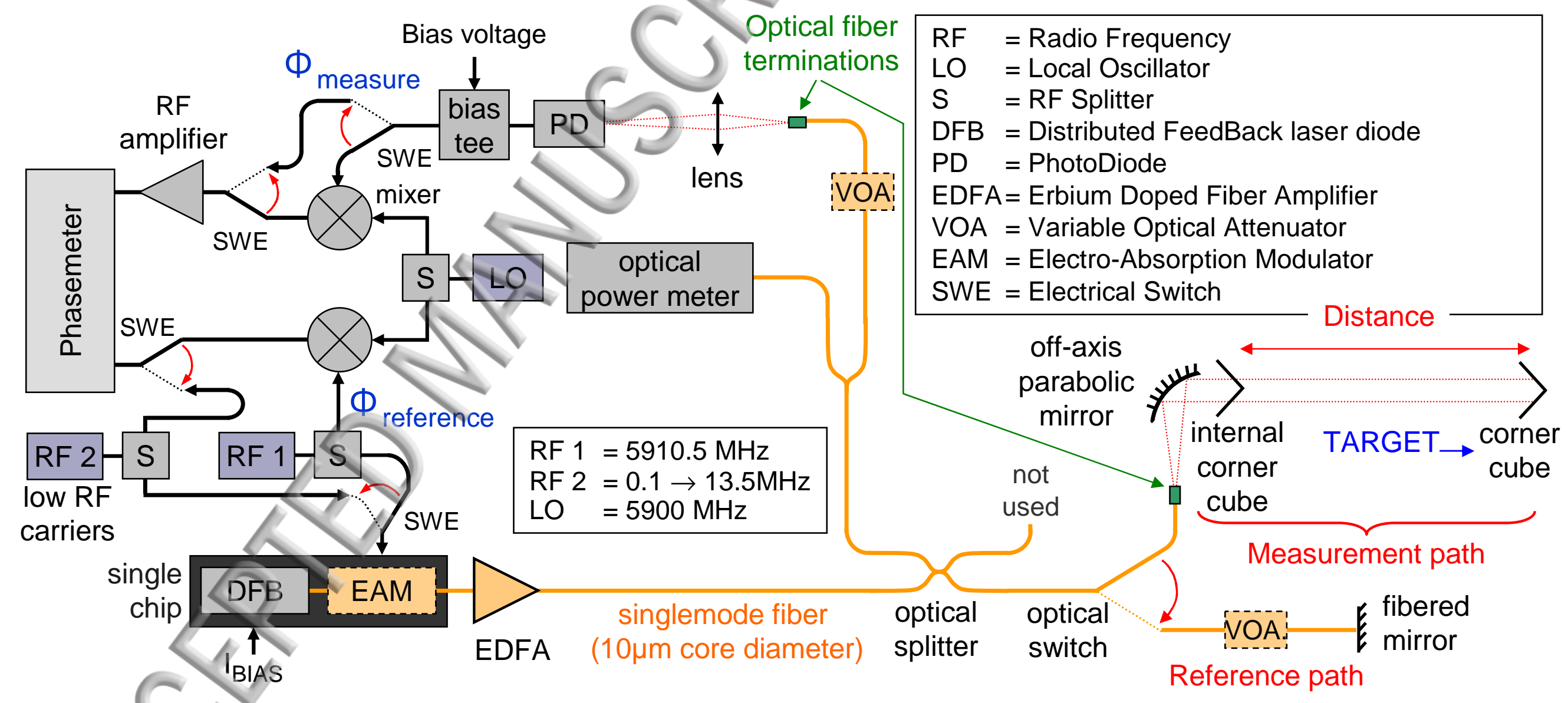




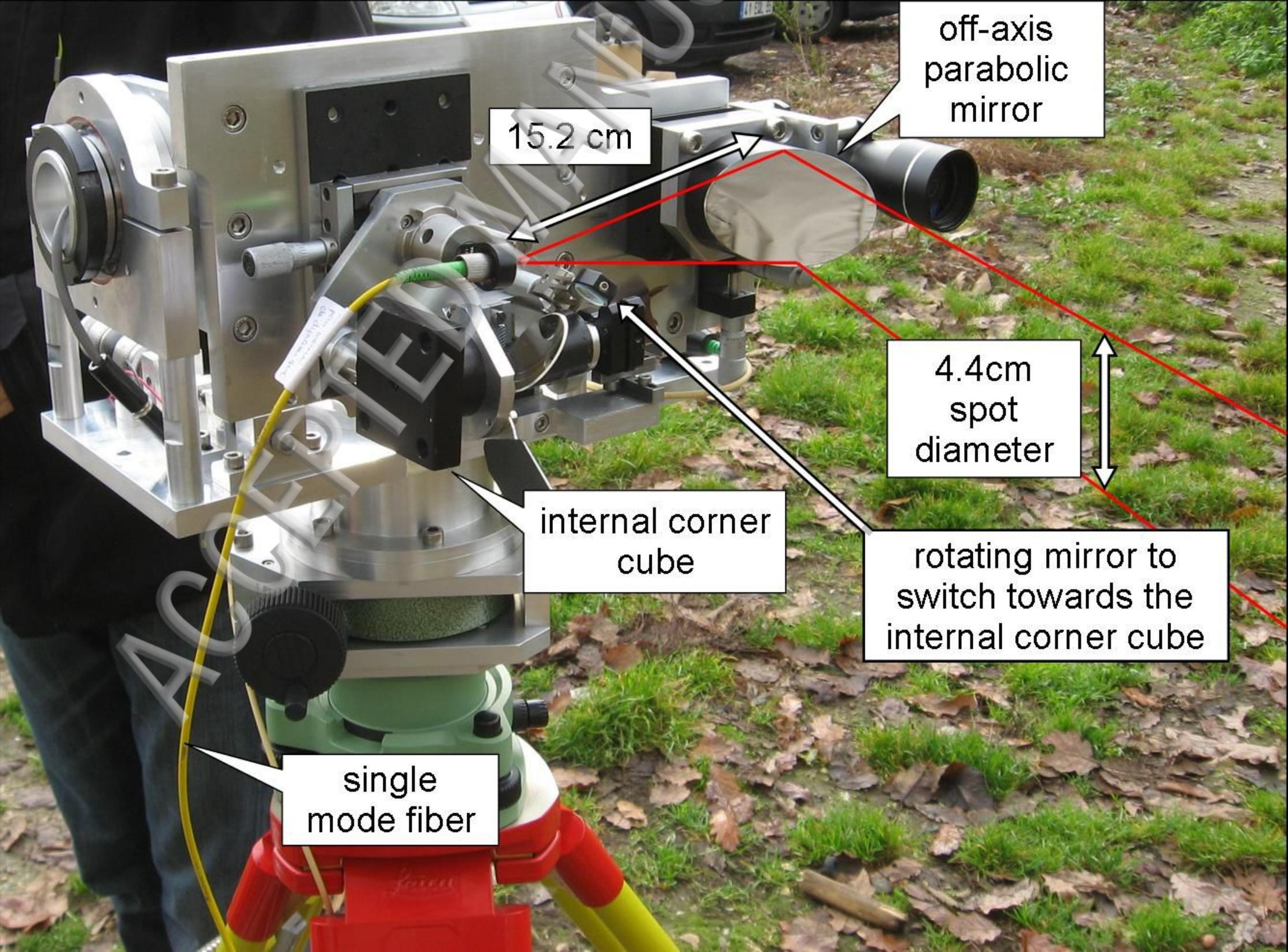




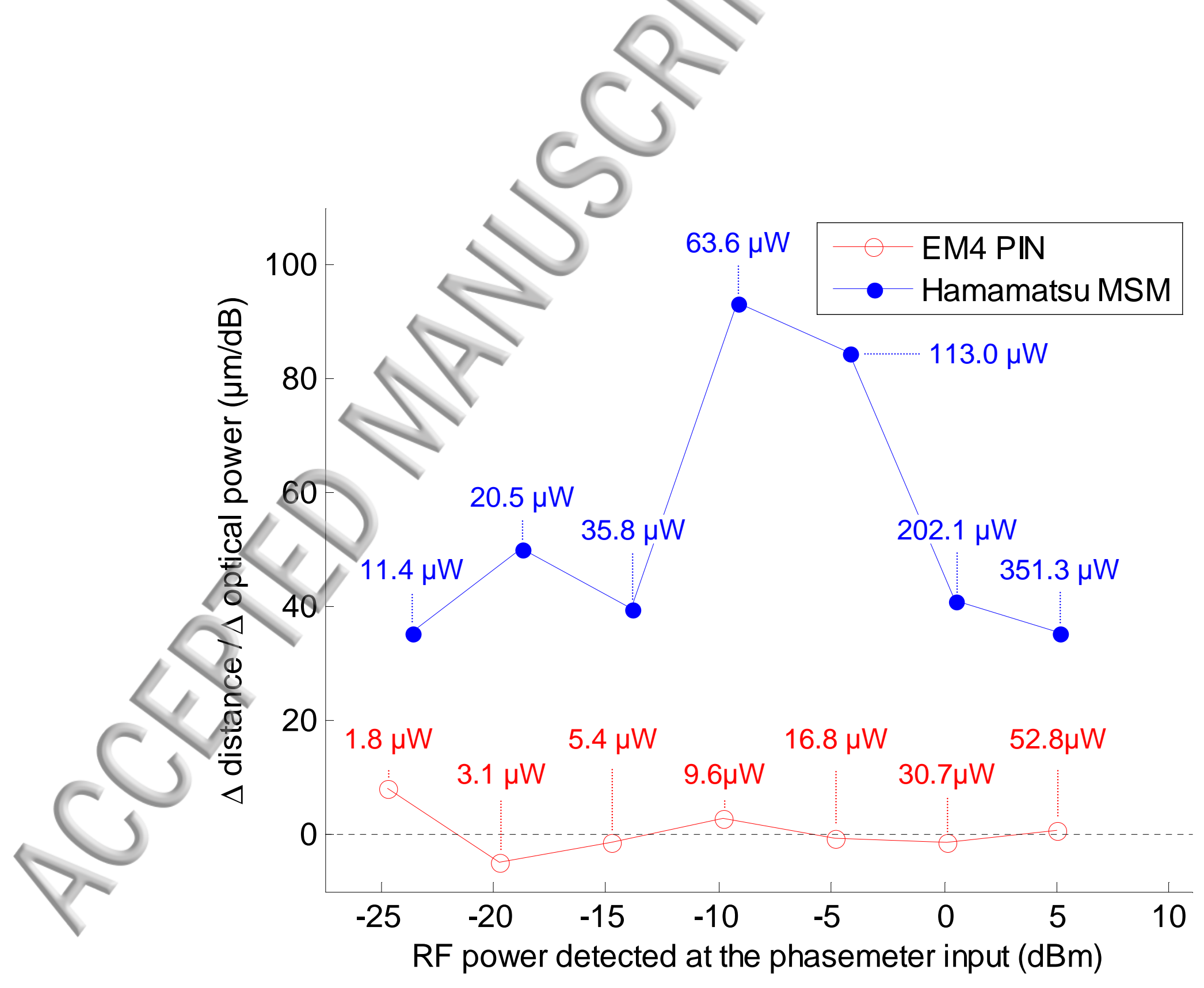




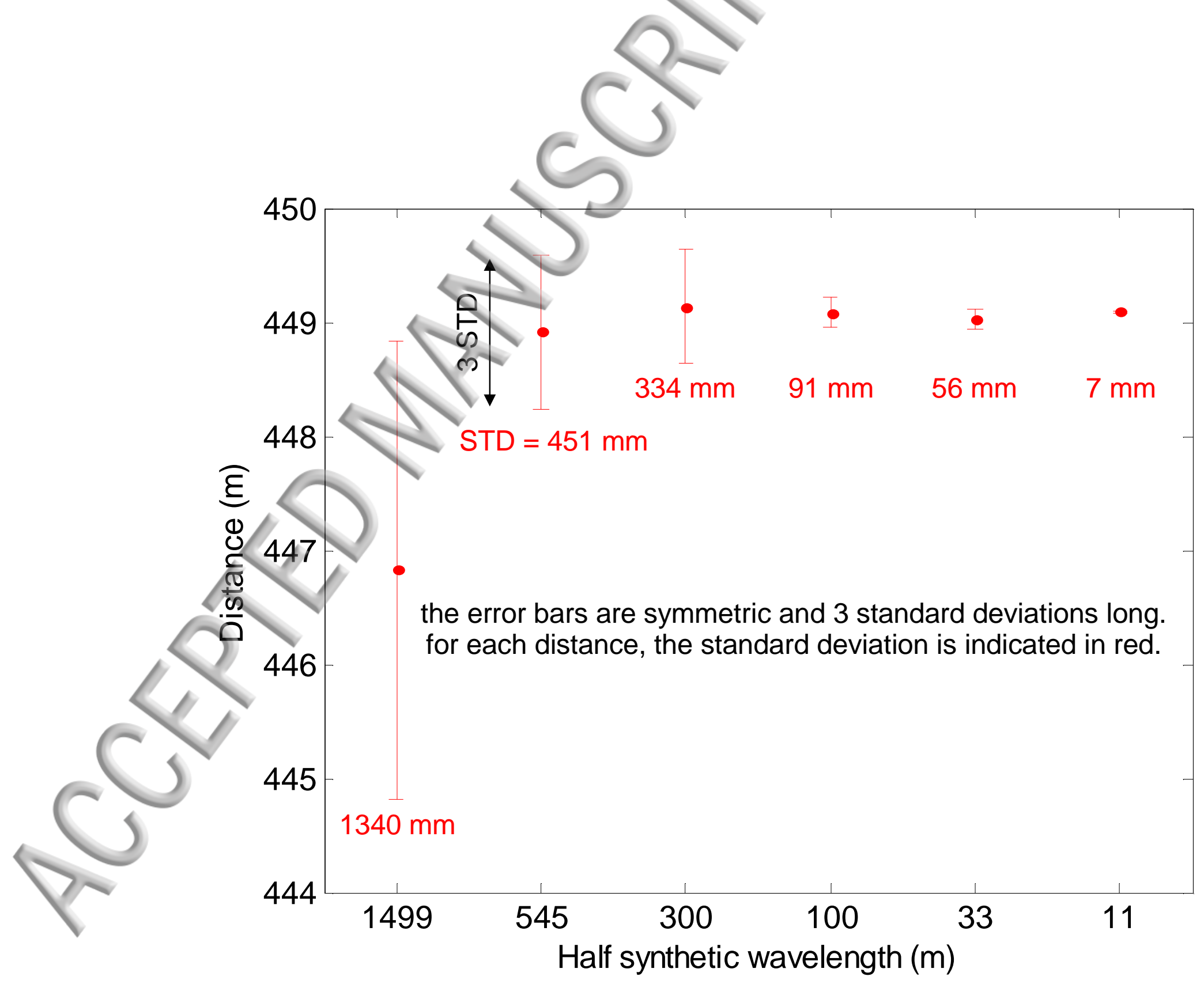




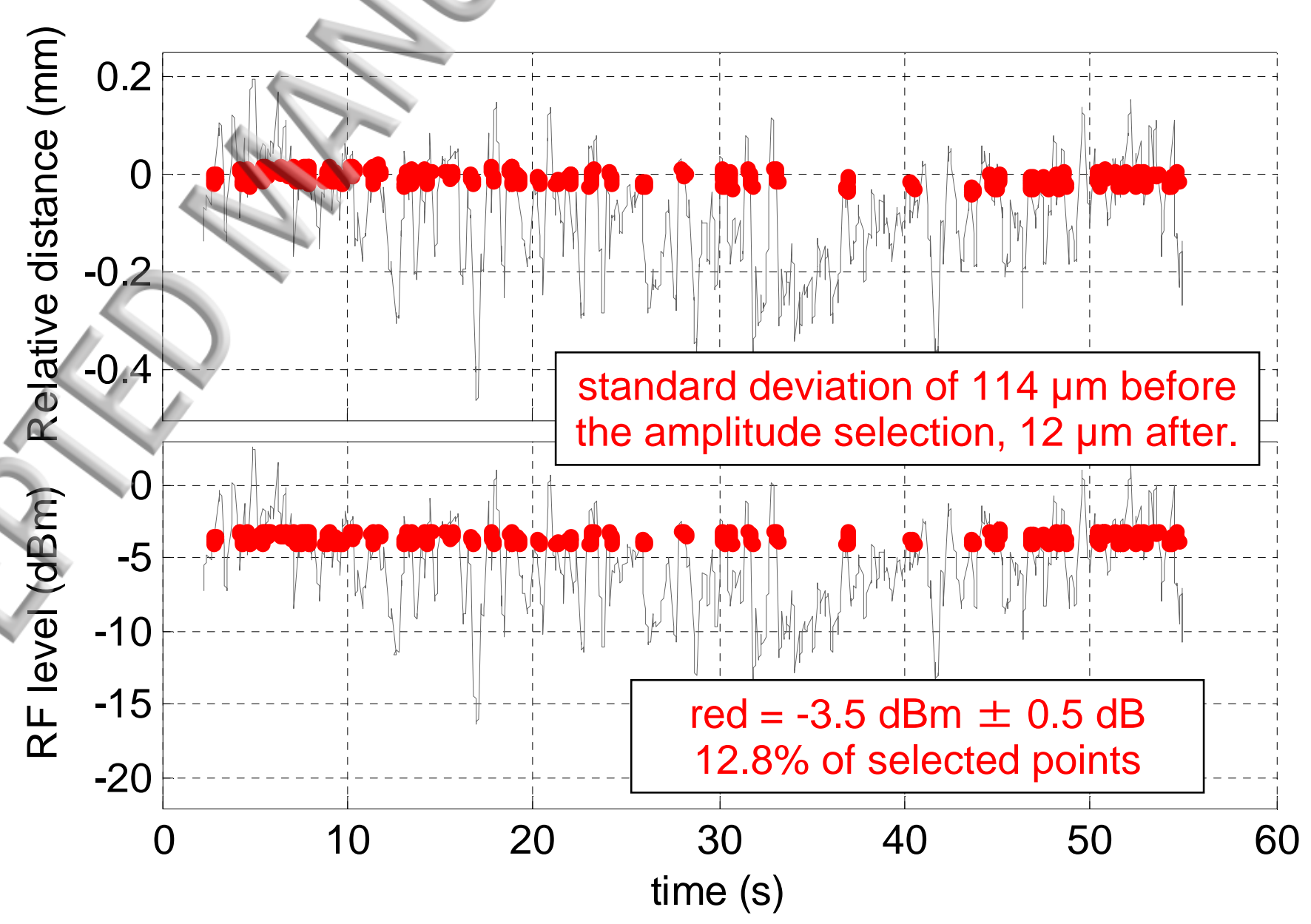




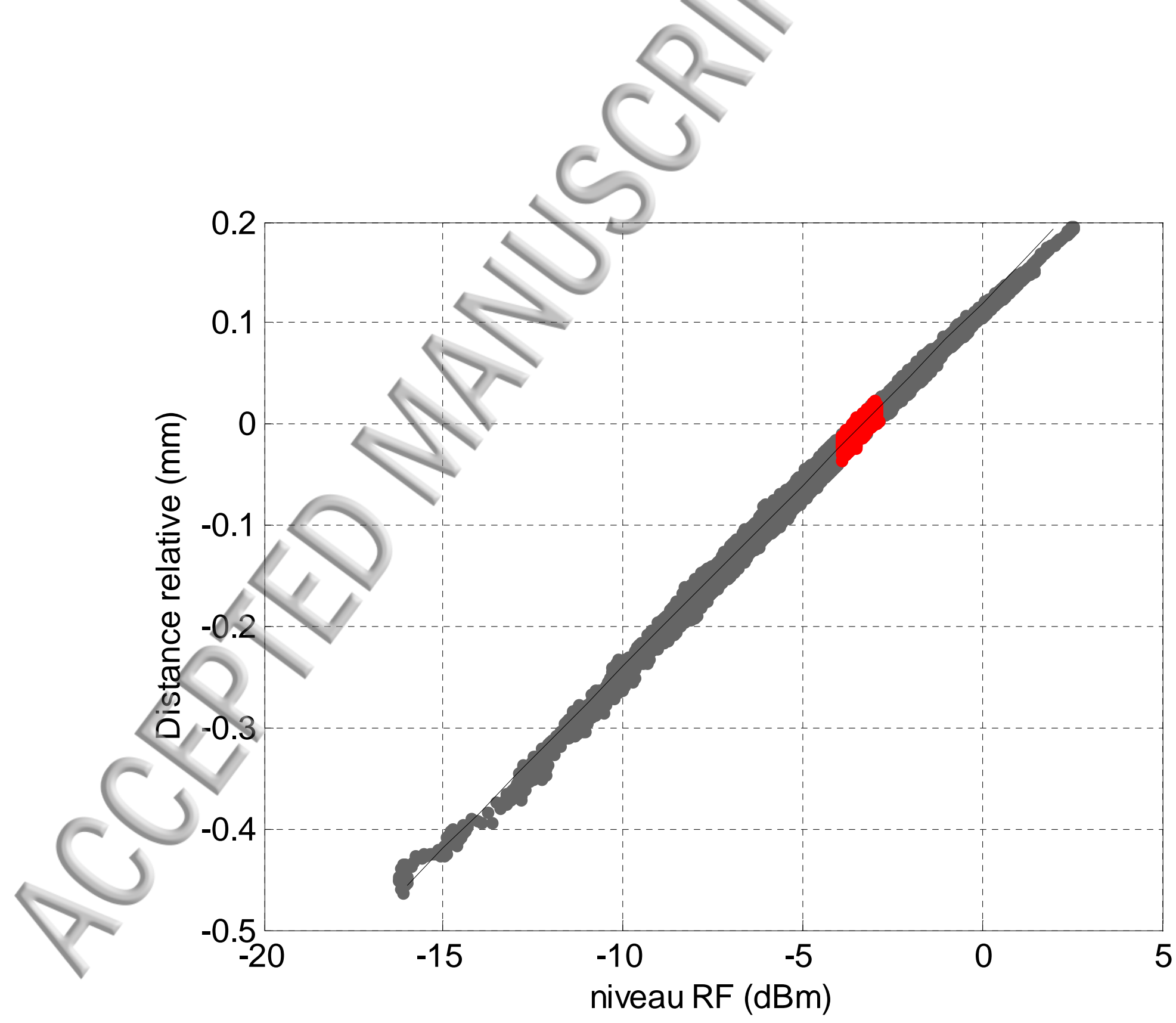




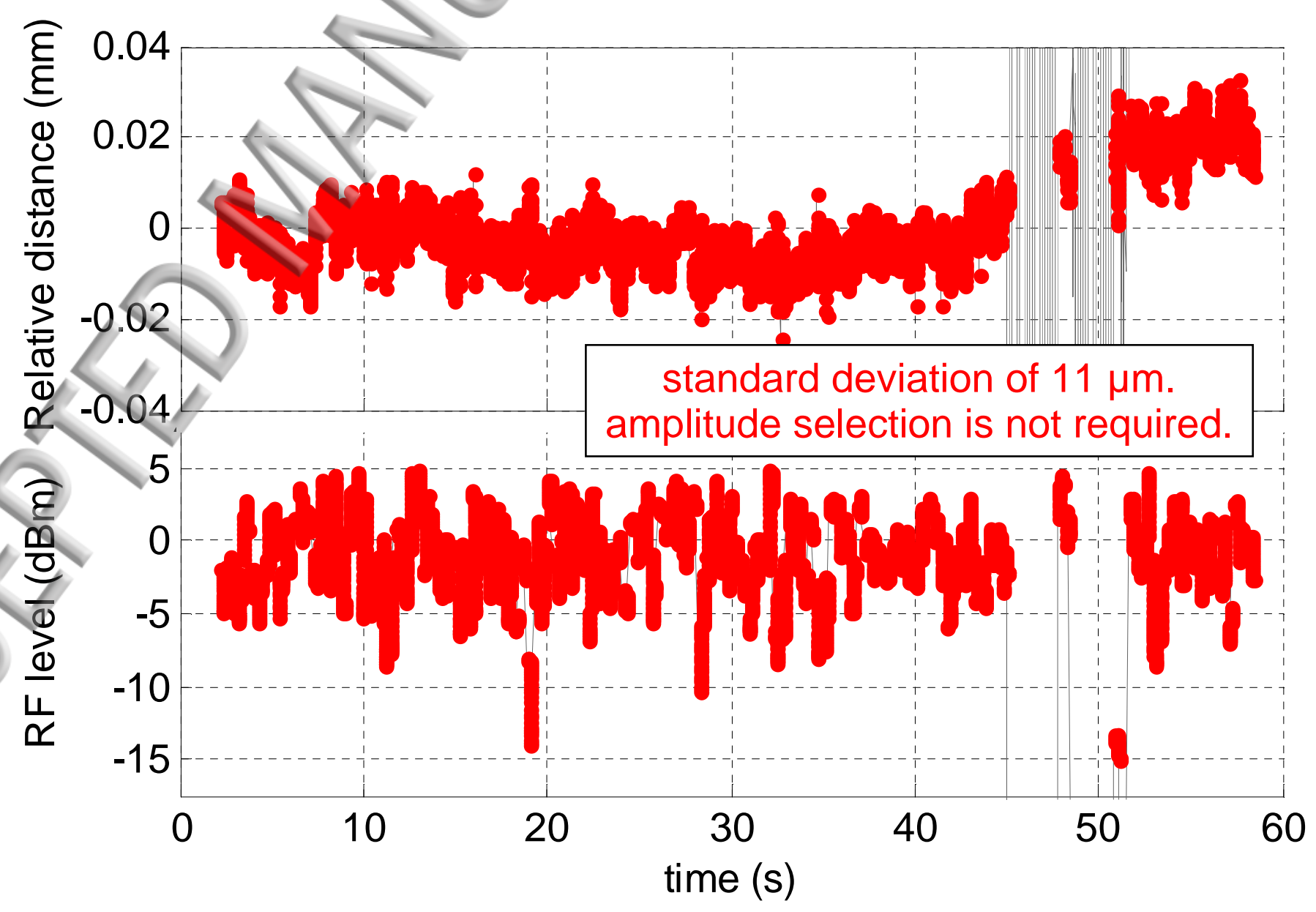




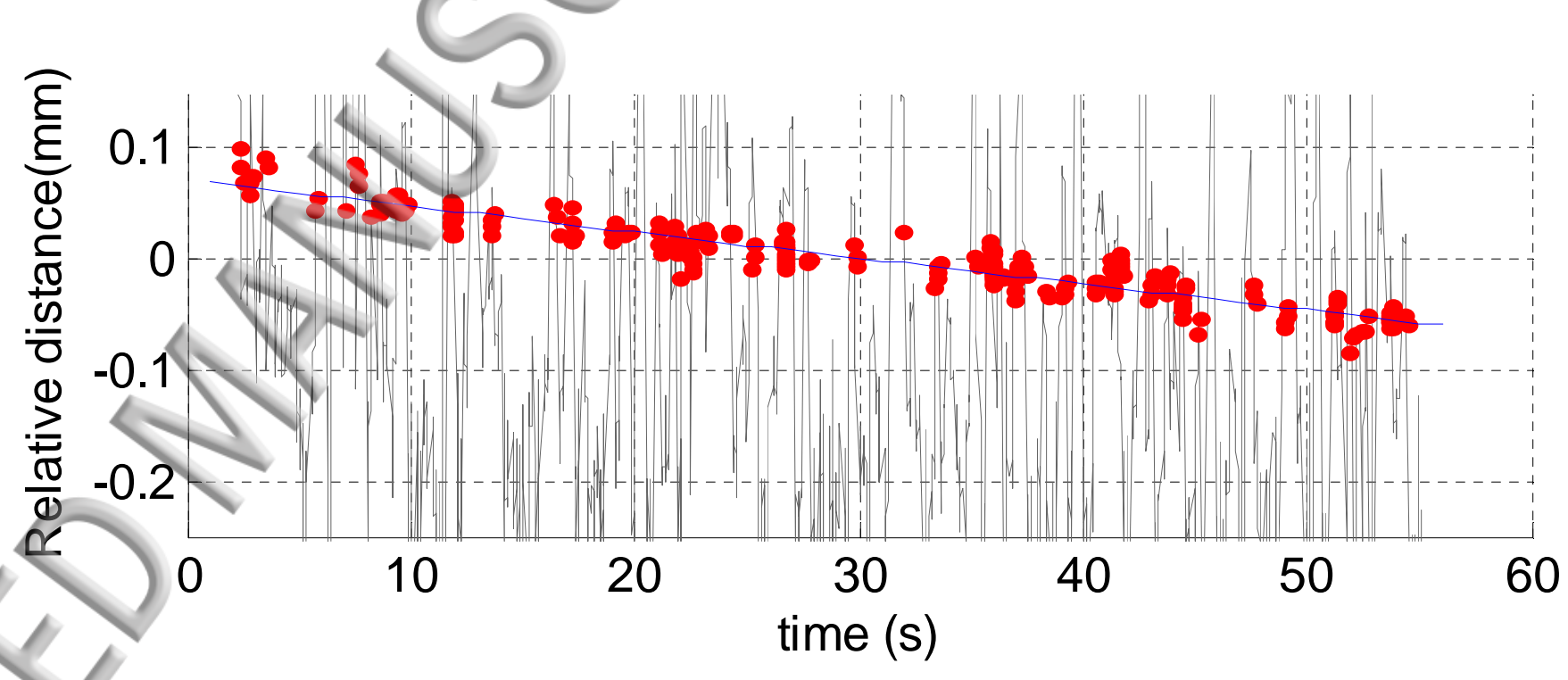




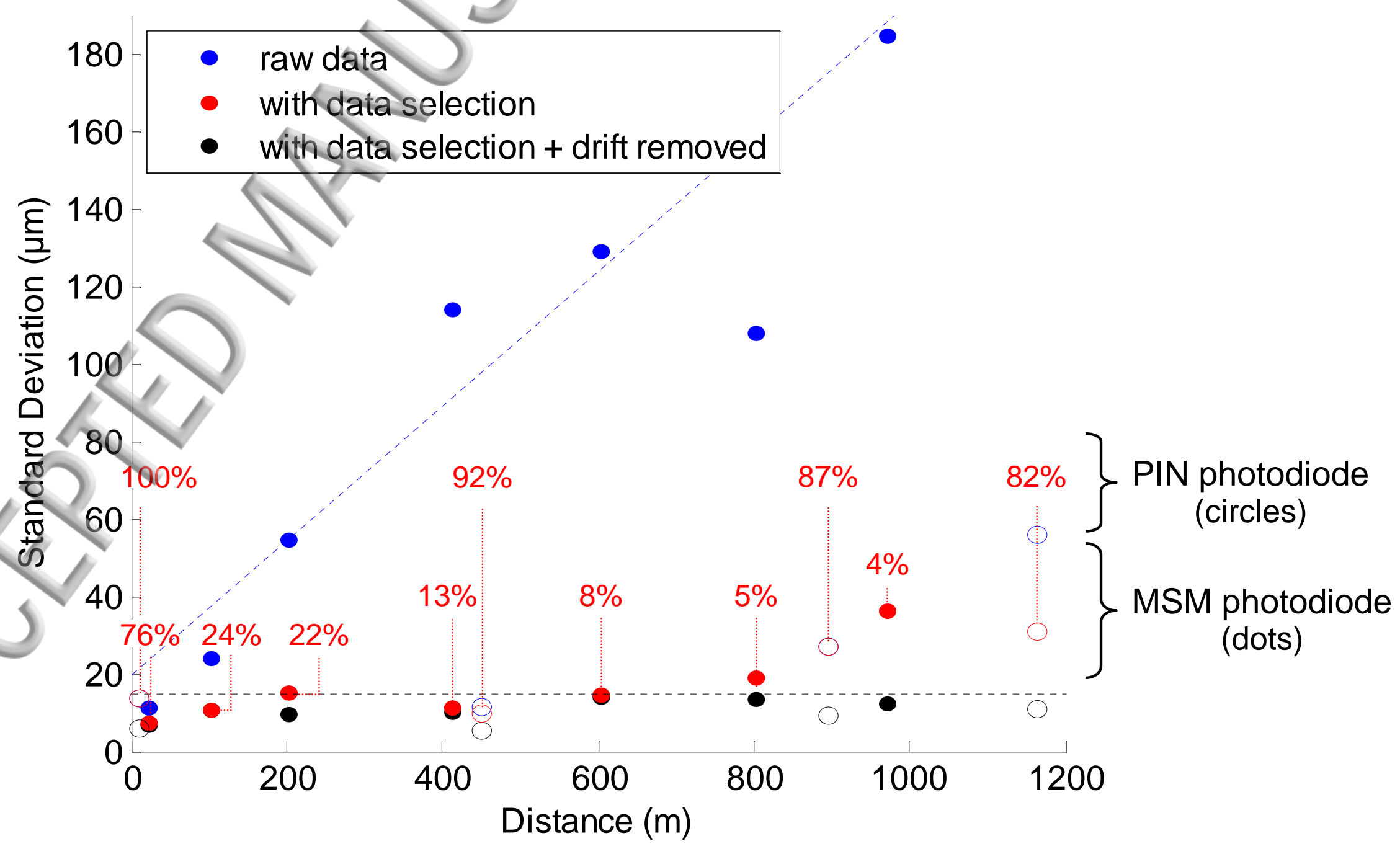

